\title{
The Study on Sustainable Development of Rural Tourism Based on the "Internet Plus" Concept
}

\author{
Qinghua Zhang ${ }^{1, a}$ \\ ${ }^{1}$ School of Management, Zhengzhou University of Industrial Technology, Zhengzhou City, Henan Province, \\ 451150, China
}

Keywords: "Internet Plus"; Rural tourism; Ecological tourism; Sustainable development

\begin{abstract}
Rural tourism is an important part of China's tourism industry, and the amount of the tourists accounted for $1 / 3$ of the total tourist reception. The coming era of the "Internet Plus" brought great changes to the rural tourism consumption, industrial development and enterprise management. Therefore, the research on the rural tourism sustainable development mode under the "Internet Plus" has far-reaching practical significance. Based on the author's study and practical experience, this paper firstly analyzed the influence of "Internet Plus" of rural ecological tourism development, and then studied the sustainable development ways for rural tourism under the background of the "Internet Plus", and finally put forward the countermeasures of sustainable development of rural tourism in "Internet Plus" era.
\end{abstract}

\section{Introduction}

After entering twenty-first Century, the Internet has experienced rapid development. Therefore, mankind has entered a new era of "Internet Plus" and "Internet Plus" has become the catalyst in the changes of all areas of industries. In 2016, the Document No.1 of the central authorities emphasized again: the whole country should vigorously develop the leisure agriculture and rural tourism, so that make it become a new pillar industry of rural prosperity and farmers' rich life. Here comes an era of " Internet Plus" with rural ecological tourism. "Internet plus" has great influence and put forward new requirements on rural ecological tourism. In the "Internet plus" era, what kind of changes that rural tourism consumption, enterprise management and industry development will have? How to make sustainable development on the rural tourism? Such problems are worthy to be discussed.

\section{The Influence from "Internet Plus" on Rural Ecological Tourism Development}

"Internet plus" improve the marketing mode of rural ecological tourism. In the "Internet Plus" era, more and more rural ecological tourists began to get information, communicate, experience and book something through the Internet by using mobile phone terminal. It makes the overall influence and change on the rural ecological tourism marketing mode. First of all, the rural ecological tourists can be more convenient to choose rural ecological tourism destination according to the personal favorite through the Internet; moreover, they can get access to the latest relative information of the tourist destination. Secondly, the rural ecological tourist destination managers and operators can be more timely to release the latest travel routes, contact ways and tourism products through the Internet. This not only reduces the cost of advertising propaganda, but also expands the information to the audience.

"Internet Plus" changed the rural ecological tourism business and consumption patterns. First of all, the rural ecological tourist consumption way has changed a lot. Further, more and more consumers choose rural ecological tourist routes and book accommodation through the mobile phone and give consumer comments feeling or write suggestions. Secondly, rural ecological tourism operators also combine their business with the Internet. The operator has changed the ideas, such as distributing leaflets, sending messages, propagating information by local radio or radio advertisement in the past. They began to use the Internet for web site or application for micro-blog and WeChat account to publish newly traveling information, which has greatly to meet the different 
needs of rural ecological tourism.

"Internet plus" promotes the development of peripheral industries of the rural ecological tourism. In the "Internet plus" era, the foundation of the wisdom rural ecological tourism development is the construction of network infrastructure. Secondly, wisdom rural ecological tourism has driven the rapid development of e-commerce in rural areas. In order to meet the needs of the consumers, rural tourism operators offer Internet Wi-Fi wireless network to solve the problems during the rural ecological tourism shopping. This led to the popularization and application of Internet technology in rural areas, so that more and more agricultural and sideline products as well as native products could sold around the country, which also promotes the vigorous development of rural e-commerce and accelerate the development of the third industry.

\section{Ways for the Sustainable Development of Rural Tourism under the Background of "Internet Plus"}

"Internet Plus" era not only can effectively solve the above problems, but also can reduce transaction costs so that to promote tourism and tourist consumption experience and modernization of rural tourism. The way of development can be divided into the following four aspects. First of all, the rural tourism under the background of "Internet Plus" can look for the tourist hot spot through public monitoring, so that to improve the marketing from the perspective of tourists; in addition, it also can adopt quantitative form to complete selection of marketing channels, and make full use of new media to attract tourists. Secondly, rural tourism has many functions, such as navigating for sightseeing, navigation, and tour guiding under the background of "Internet Plus". Tourists can browse the relevant information online to develop appropriate itinerary in advance, and then complete the booking of travel products, payment and evaluation. In addition, it can also develop targeted tourism services, such as weather forecast, traffic and live online viewing reminder according to the requirements of tourists, so that the rural tourism service quality was greatly improved. Thirdly, rural tourism can realize the integration of various resources to further promote the rural public service level, the overall social intelligence level and the level of emergency treatment under the background of "Internet Plus". As a result, the rural tourism is more safe, efficient and scientific. Fourth, rural tourism can realize the real-time control of the tourism enterprises and tourists, and then make more timely scientific management so that to effectively prevent the occurrence of post processing and passive management issues under the background of "Internet Plus".

\section{Sustainable Development Countermeasures of Rural Tourism under "Internet Plus" Era}

Government guided, scientific planning and stereo supported program. First of all, the government should make scientific plan, development plan of wisdom rural tourism, general framework and related policies. They should encourage and guide enterprises to do the rural tourism informatization construction and development of wisdom rural tourism through the active policy and financial support. Secondly, the government should strengthen the construction of rural infrastructure and improve the wisdom of tourism, focusing on strengthening environmental remediation, road construction, green construction, network construction and catering, accommodation, entertainment, health, infrastructure and supporting facilities. Again, the government should conduct the construction of wisdom rural tourism in one center and four platforms, realizing the rural tourism industry data integration, scenic spots real-time monitoring, remote video monitoring and online viewing, tourism vehicle GPS location management, accommodation reception of real-time statistics, tourism tourism safety operation regulation, emergency management and personnel network the training and other intelligent functions.

Build a platform to promote rural tourism O2O. In 2015, The government work report clearly pointed out that we should vigorously promote tourism leisure consumption, and boom the emerging consumer online and offline interaction. Rural tourism is the future development trend of leisure tourism, and also is a typical representative of the emerging consumption. Rural tourism 
$\mathrm{O} 2 \mathrm{O}$ will become the future trend and a new business model which cannot be halted. Rural tourism $\mathrm{O} 2 \mathrm{O}$ can make full use of the advantages of the Internet, and integrate of rural resources to achieve seamless connection online and offline and to meet the individual needs of tourists with improving the traveling experience quality. It has incomparable advantages that a traditional rural tourism business model can not match.

Integrate of resources and make innovative products and services using the Internet thinking. At present, rural tourism is in the secondary-perfect stage of the product, and tourism destination is still relatively primitive, among which most are still stuck in the condition of eating farmhouse meal, picking some vegetables and fruits to barbecue, fishing, seeing mountain on crops. With the coming of the "Internet Plus" era, rural tourism ushered in a new driving force, which needs to re-examine and think about the rural tourism market, product, service and management. This requires a sense of innovation and differentiation consciousness on learning the use of the Internet and analysis of other visitors voice by means of internal and external information, looking for product innovative ideas so that to build rural tourism "network model" and step on the road of creative cultural brand like "Chu orange" and "selling Meng". "Internet Plus" era needs innovative and intelligent tourism products that can highlight the characteristics of rural tourism resources and contain rural cultural connotation of diversification and individuation.

Promote and start a new mode of marketing wisdom. At present, rural tourism marketing is generally not done well; it is also one of the rural tourism development shortcomings. On the one hand, it is lack of human and financial resources; on the other hand, it is lack of the knowledge and application of the new media. In the "Internet Plus" era, rural tourism needs to adopt the new model of smart marketing to create marketing platform of rural tourism wisdom; the key elements of rural tourism attraction, such as colorful scenery style, unique folk customs, wonderful stories and special material products, which also need network terminal, mobile phone terminal, large screen and other marketing channels of publicity to carry forward.

Conduct cooperation and establish a sound security system. First, we should establish and perfect the wisdom rural tourism environmental protection system, strengthen environmental industry and environmental health in the rural tourism community through water quality detector, air quality sensor, temperature and humidity sensors and other equipment, which conducted by Environmental Protection Bureau and the Bureau of Meteorology and coordinated by Rural tourism community and rural tourism industry. Second, we should establish and perfect the rural wisdom tourism traffic security system, so that to realize the real-time dynamic monitoring of rural tourism traffic, improve traffic efficiency and ensure the safety of tourist traffic. This requires the coordination of the transport department with GPS technology by using RFID technology, image technology to identify the high-speed automatic identification of vehicles and the surrounding rural tourism community, dynamic monitoring and traffic prediction. Moreover, we can make effective guidance and control to traffic flow, and make the full realization of rural tourism traffic informationization, networking and intelligence through traffic information service, route guidance and traffic signal control. Third, we need to establish and perfect the rural medical care system, so that to provide the wisdom medical and health services for tourists. For example, we should open the online medical information services on the Internet, setting up medical rescue station in the rural tourism and the surrounding communities and develop a key emergency intelligent terminal.

\section{Summary}

With the continuous development of the "Internet Plus", it has gradually become the main force to promote economic development, and gradually penetrated into various fields, which plays an important role in the company's products, market, business ecology and management mode. As the rapid developing economic mode in recent years, the rural tourism should conform to the development of the Internet Plus "and the depth of integration, product innovation, quality promotion, marketing, service and management wisdom aspects so that to promote the transformation and upgrading of rural tourism and achieve sustainable development. 


\section{References}

[1] Dong Yindi. The Connotation and Competitiveness of "Internet Plus Travel"[J]. Electronic Technology and Software Engineering, 2017, (05): 9.

[2] He Xin. An Analysis of the Development of Tourism Internet Plus Initial Condition[J]. The Financial Times, 2016, (14): 171.

[3] Xiao Yuanping, Gong Xiang. The Research on the Development of Guizhou Tourism Industry from the Perspective of "Internet Plus Wisdom "[J]. Guizhou Social Science, 2016, (05): 127-132.

[4] Li Min. New Opportunities for the Development of Agricultural Tourism in China under "Internet Plus" Era[J]. Chinese of Business Research, 2016, (11): 118-120.

[5] Mao Feng. The Path and Countermeasures of Sustainable Development of Rural Tourism under "Internet Plus" Era[J]. Reform and strategy, 2016,(03):74-77.

[6], Xu Jinhai, Wang Jun. Study on the Integration of Tourism Industry under "Internet Plus" Era[J]. Research on Financial and Economic Issues, 2016, (03): 123-129.

[7] Li Shi, Huang Anmin, Li Hao, Huang Xiang. Internet Plus Travel: Creative Tourism, Tourism and Financing Platform Integration[J]. Technology and Industry, 2016, (02): 34-40+45. 